\title{
A choice experiment approach to the valuation of air pollution in Mashhad, Iran
}

\author{
M. Ghorbani ${ }^{1}$, S. Kulshreshtha ${ }^{2} \&$ A. Firozzarea ${ }^{1}$ \\ ${ }^{1}$ Department of Agricultural Economics, \\ Ferdowsi University of Mashhad, Mashhad, Iran \\ ${ }^{2}$ Department of Bioresource Policy, Business and Economics, \\ University of Saskatchewan, Saskatoon, Canada
}

\begin{abstract}
This study describes the results of a survey carried out in Mashhad, Iran. The survey was designed using choice-modeling techniques and intended to discover what valuation Mashhad residents placed on air pollution and the abatement of air pollution. The survey results were analyzed using a nested logit (NL) model. This analysis then allowed a consideration of the improvements in household welfare that might be expected under different scenarios of air pollution control. Researchers sampled two populations: inhabitants of areas with high air pollution and inhabitants of areas of moderate pollution. The results indicated that the inhabitants of the areas suffering the worst air pollution had the highest willingness to pay (WTP) for a reduction in pollution.
\end{abstract}

Keywords: air pollution, choice modeling approach, nested logit model, household welfare, Iran.

\section{Introduction}

Ever since the start of the Industrial Revolution, economic development and environment have been at odds with each other. According to the WCED [1], current environmental trends, if continued, will radically alter the planet and threaten the lives of many species upon it. As awareness of the danger has grown, environmental protection has been increasingly recognized as a principle concern (Gurluk [2]).

One alarming environmental trend in Iran is an increase in air pollution in major cities and the surrounding countryside. This has led to an increased public 
awareness of the problems resulting from air pollution. Much pollution is due to automobiles, factories, and household cooking fuels. In many densely populated areas this pollution is a cause of poor health (due mainly to high particulate count in the air and foul odours) and reduced visibility (Dagsvik et al. [3]).
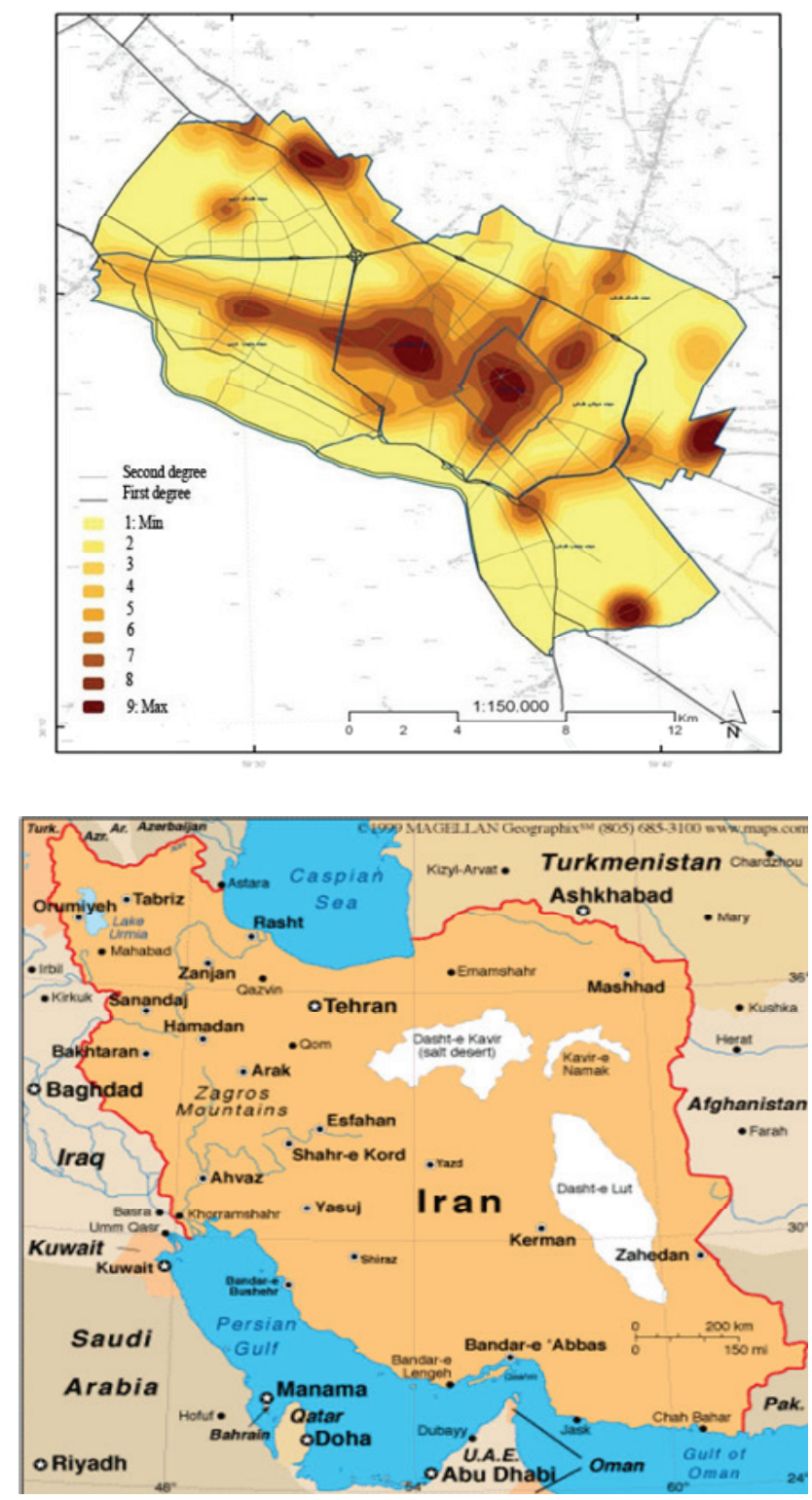

Figure 1: Distributions of air pollution in Mashhad zones (top); map of Iran showing location of Mashhad (bottom). 
One of the reasons for the lack of policies to protect the environment is the lack of understanding by decision-makers of the social impact of environmental degradation. This is partly a result of a lack of information available on the economic value of the environment, since it is not recognized by the usual market-based valuations. Such valuations are not easily ascertainable. However, in recent years, a number of methods have been developed to assign economic values to environmental resources, and to integrate those values in the decisionmaking process. Choice experiment approach (CEA) is one of these methods (Gurluk [2]).

Pollution is a major problem in Iran in general and in the city of Mashhad in particular. Mashhad is located in Khorasan Razavi province, in the northeastern corner of Iran (Figure 1). It is Iran's second-largest city, second in size only to Tehran, Iran's capital. It is a center of pilgrimage (to the shrine of Imam Reza) and of industry. The city and its suburbs cover an area of approximately $204 \mathrm{~km}^{2}$. The city is located on a plain between two long ridges: Binalood to the south and southwest and Hezarmasjed to the north and northeast. It is 985 meters above sea level and has a semi-temperate climate. For some 270 to 300 days of the year, it is subject to temperature inversions that hold smog over the city Mousavi [4]. Mashhad's air pollution is primarily a result of human activities and is caused mainly by emissions from motor vehicles. There are 294,608 motor vehicles in the city, of which 272,137 are powered by gasoline. The remaining 42,462 vehicles operate on diesel fuel (Mousavi [4]). There are also natural sources of pollution, such as dust and pollens.

The primary objective of our research is to estimate the willingness to pay (WTP) of the Mashhad population for reduction of air pollution.

\section{Study methods}

\subsection{Environmental valuation methods and the choice modeling approach}

Although not typically monetized, ecosystem goods and services do contribute to an individual's utility and they therefore have value. This value can be measured by the individual's maximum willingness-to-pay (WTP) for such goods and services (Loomis et al. [5]). The only methods that are capable of estimating non-use values of air pollution effects are the contingent valuation method (CVM) and the choice experiment approach (CEA) (Gurluk [2]). The latter approach has some advantages over CVM, as it can be used to value a selection of possible outcomes and to assess the tradeoffs between outcomes that individuals might be willing to make.

Choice experiments are one example of the stated preference approach to environmental valuation, in as much as they involve eliciting responses from individuals to researcher-constructed, hypothetical markets and do not require the study of actual behavior. The CE approach is based on random utility theory (RUT) and the characteristics theory of value. Environmental goods are valued by reference to their attributes (instruments of choice set definition), which are evaluated by applying probabilistic models to choices between different possible 
scenarios. Our decision to use the $\mathrm{CE}$ approach was driven by the desire to estimate values for different aspects of air quality. These aspects constitute the attributes of interest in the $\mathrm{CE}$ design detailed below.

In a $\mathrm{CE}$, the status quo and a number of alternatives are described (Muller and Diener [6]). Respondents are asked to state which of the alternatives they most prefer. Using appropriate statistical techniques, one can infer an index function from the responses. This function is the best predictor of the observed choices (Green [7]). This technique builds on the conjoint metric analysis methodology developed in the field of marketing and introduced into the environmental economics literature by Adamowicz et al. [8].

\subsection{Study site}

The current study is focused on air pollution issues in Mashhad. This city is a big populated city and located in north-east of Iran on a plain between Binalood and Hezar-Masjed heights. This city is home to more than 2.5 million people. In addition to this, this city receives over 14 million religious pilgrims annually. Table 1 reports the priorities of air pollutant sources of Mashhad.

Table 1: $\quad$ Sources of pollutants, ranked by output.

\begin{tabular}{|c|c|}
\hline Source & Priority \\
\hline Vehicles & 1 \\
\hline Indoor & 1 \\
\hline Commercial & 1 \\
\hline Industries (inside the city) & 1 \\
\hline Filling stations (inside the city) & 1 \\
\hline Trains & 2 \\
\hline Planes & 3 \\
\hline Filling stations(outside the city) & 4 \\
\hline Industries (outside the city) & 4 \\
\hline
\end{tabular}

In addition to thermal inversion, air stability and lack of rain, we should acknowledge that the most important factor of Mashhad air pollution is manmade pollutions like automobiles, factories and other pollutants. Based on statistics of environment office of Khorasan Razavi province about 72 percent of Mashhad air pollution is because of motor-vehicles traffic. In this metropolis about 800 thousands motor-vehicles are in traffic. Moreover, there are many polluting units like factories, compost plants, in Mashhad suburbs which are not compatible with dominant winds.

It is worth noting that distribution of air pollution in Mashhad differs in various times and zones of the city. Air pollution measurement through 12 measurement stations which are observing and registering Mashhad air pollution status shows that air pollution is more critical in Qale-sakhteman, 
Panjrah, Shohada and Sajad regions. Furthermore, early morning hours of a day due to lack of ascending currents in big and industrial cities like Mashhad are more polluted. Thermal inversion and air stability bring about more air pollution in fall and spring rather than other seasons.

According to many physicians the reason of many diseases including gastrointestinal, heart, respiratory and vascular diseases in Mashhad is breathing polluted air. For this reason, some people with heart and respiratory diseases are advised not to leave their homes. Air pollution in Mashhad is responsible for a number of negative effects. It has been proved that air pollution can affect human health. These health effects include increased hospital admissions due to the exacerbation of cardiac and respiratory diseases, as well as increased mortality. In addition to adverse health effects, air pollution here creates poor visibility, black fallout and bad odours.

\subsection{Data collection plan}

Based on consultation with staff of environment office of Khorasan Razavi province, this study stratified Mashhad into two regions; high-polluted region and medium-polluted region. Stratified random sampling method was used to select sample residents. The main survey consisted of 160 and 126 households in the high polluted and medium polluted split samples, respectively.

\subsection{Choice experiment design}

In consultation with the staff of the Khorasan Razavi Environment Office, researchers chose four important measures of air pollution damage, called attributes, or instruments of choice set definition. They are outlined in Table 2. Measures included health effects (increase in hospital admissions due to cardiorespiratory diseases and increased mortality) and the numbers of days that

Table 2: $\quad$ Attribute levels used in choice experiment design.

\begin{tabular}{|c|c|c|c|}
\hline Attribute & Current situation & $\begin{array}{c}\text { About } 30 \text { percent } \\
\text { better }\end{array}$ & $\begin{array}{c}\text { About } 30 \\
\text { percent worse }\end{array}$ \\
\hline $\begin{array}{c}\text { Health } \\
\text { effects }\end{array}$ & $\begin{array}{c}\text { 18 extra hospital admissions } \\
\text { and 2 extra deaths per month, } \\
\text { compared to figures expected if } \\
\text { the air were perfectly clean }\end{array}$ & $\begin{array}{c}12 \text { extra hospital } \\
\text { admissions and 1 } \\
\text { extra death per } \\
\text { month }\end{array}$ & $\begin{array}{c}24 \text { extra } \\
\text { hospital } \\
\text { admissions and } \\
3 \text { extra deaths } \\
\text { per month }\end{array}$ \\
\hline $\begin{array}{c}\text { High } \\
\text { particulate } \\
\text { count }\end{array}$ & 3 days per month & 2 days per month & $\begin{array}{c}4 \text { days per } \\
\text { month }\end{array}$ \\
\hline Foul odors & 4 days per month & 3 days per month & $\begin{array}{c}5 \text { days per } \\
\text { month }\end{array}$ \\
\hline $\begin{array}{c}\text { Reduced } \\
\text { visibility }\end{array}$ & 3 days per month & 2 days per month & $\begin{array}{c}4 \text { days per } \\
\text { month }\end{array}$ \\
\hline
\end{tabular}


Mashhad residents were warned of heavy particulate load, foul odours, or reduced visibility. In order to estimate WTP, survey respondents were asked to choose between possible changes in monthly taxes. These constitute the fifth attribute.

The survey was designed to elicit responses to three levels of each attribute. The middle level was based on the current level of pollution or property tax. The other two levels were based on a 30 percent reduction or a 30 percent increase in pollution levels; each level was paired with an increase, a decrease, or no change in monthly property taxes. The final survey comprised twenty-seven different choices; alternatives were combined with the baseline, the current state of affairs, into nine separate choice sets.

\subsection{Statistical model}

Although the logit-based models are based on RUT (Ortuzar and Willumsen [9]), the majority of past studies have not progressed beyond using the simple multinomial logit (MNL) model. While the independently and identically distributed (IID) assumption and the behaviorally comparable assumption of Independence of Irrelevant Alternatives (IIA) allow for ease of computation, violations of both of these assumptions can and do occur. When violations do occur, the cross-substitution effects observed between pairs of alternatives are no longer equal, given the presence or absence of other alternatives within the complete list of available alternatives within the model (Hensher et al. [10]). This property (IIA) states that the relative probabilities of two options being selected are unaffected by the introduction or removal of other alternatives. This property follows from the independence of the error terms across the different options contained in the choice set. If a violation of the IIA hypothesis is observed, then more complex statistical models are necessary. The model that relaxes some of the assumptions is the nested logit, model. Furthermore, there are numerous formal statistical tests that can be used to test for violations of the IIA assumption, with the test developed by Hausman and McFadden [11].

One way to relax the homoscedasticity assumption in the conditional logit model (one which also provides an intuitively appealing structure) is to group the alternatives in subgroups that allow the variance to differ across the groups while maintaining the IIA assumption within the groups. This specification defines a Nested Logit model. Thus, it is useful to think of this specification as a two-level choice problem. Suppose that the J alternatives can be divided into L subgroups such that the choice set can be written as follows:

$$
\left[c_{1}, \ldots, c_{J}\right]=\left(c_{1 / 1}, \ldots, c_{j 1 / 1}\right), \ldots,\left(c_{1 / L}, \ldots, c_{J L / L}\right)
$$

Logically we may think of the choice process as that of choosing among the $\mathrm{L}$ choice sets and then making the specific choice within the chosen set. This method produces a tree structure.

Suppose as well that the data consists of observations on the attributes (used in the technical sense) of the choice $X_{j / l}$ and attributes of the choice sets $Z_{1}$. In order to derive the mathematical form of the model, we begin with the unconditional probability: 


$$
\operatorname{prob}\left[\text { twig }_{j}, \text { branch }_{l}\right]=p_{j l}=\frac{e^{\beta^{\prime} x_{j / l}+\gamma^{\prime} z_{l}}}{\sum_{l=1}^{L} \sum_{j=1}^{J_{l}} e^{\beta^{\prime} x_{j / l}+\gamma^{\prime} z_{l}}}
$$

Now write this probability as:

$$
p_{j l}=p_{j / l} p_{l}=\left(\frac{e^{\beta^{\prime} x_{j / l}}}{\sum_{j=1}^{J_{l}} e^{\beta^{\prime} x_{j / l}}}\right)\left(\frac{e^{\gamma^{\prime} z_{l}}}{\sum_{l=1}^{L} e^{\gamma^{\prime} z_{l}}}\right) \frac{\left(\sum_{j=1}^{J_{l}} e^{\beta^{\prime} x_{j / l}}\right)\left(\sum_{l=1}^{L} e^{\gamma^{\prime} z_{l}}\right)}{\left(\sum_{l=1}^{L} \sum_{j=1}^{J_{l}} e^{\beta^{\prime} x_{j / l}+\gamma^{\prime} z_{l}}\right)}
$$

Define the inclusive value for the $l^{\text {th }}$ branch as:

$$
I_{l}=\ln \sum_{j=1}^{J} e^{\beta^{\prime} x_{j / l}}
$$

Then after canceling terms and using this result, we find:

$$
\begin{aligned}
& p_{j / l}=\frac{e^{\beta^{\prime} x_{j / l}}}{\sum_{j=1}^{J l} e^{\beta^{\prime} x_{j / l}}} \\
& p_{l}=\frac{e^{\gamma^{\prime} z_{l}+\tau_{l} I_{l}}}{\sum_{l=1}^{L} e^{\gamma^{\prime} z_{l}+\tau_{l} I_{l}}}
\end{aligned}
$$

The new parameters $\tau_{l}$ must equal 1 to produce the original model (conditional logit model). The coefficients in this model are not directly interpretable Green [7]. The estimated coefficients of the attributes can be used to estimate the tradeoffs that respondents would be willing to make between various attributes. The price attribute can be assessed in conjunction with the other attributes to determine the WTP of respondents for gains or losses of selected attribute levels. This monetary value is called the implicit price of the attribute (Bergman et al. [12]) and can be expressed as:

$$
W T P=-\left[\begin{array}{cc}
b_{\text {non }}-\text { market } & \text { attribute } \\
b_{\text {monetary }} \text { attribute }
\end{array}\right]
$$

\subsection{Economic surplus}

One of the advantages of choice experiments is that estimated coefficients of the attributes may be used to estimate the economic value of different attribute combinations. In order to determine the change in economic surplus from 
possible alternative scenarios in a multi-attribute nested logit model, a utility difference is calculated as:

$$
\text { Economic surplus }=-\frac{1}{b_{y}}\left(V_{i}^{1}-V_{i}^{2}\right)
$$

where, $b_{\mathrm{y}}$ is the marginal utility of income and $\mathrm{V}_{\mathrm{i}}$ is the indirect utility associated with alternative i. The superscript 1 represents the current situation and superscript 2 represents other scenarios.

\section{Results}

\subsection{Results of estimation}

In order to test the violation of the IIA assumption, the Hausman test was used for both highly-polluted and moderately-polluted areas. The IIA was firmly rejected in both heavily and moderately polluted areas. This suggests that constructing the model as a simple conditional logit could generate misleading results. For this reason, researchers used nested structures.

Results from the nested logit models are presented in Table 3. The coefficients are parameters of the indirect utility function, notwithstanding the fact that they are confounded with a scale parameter. This makes it possible to interpret them directly. Coefficient signs show the influence of attributes on choice probabilities.

Table 3: $\quad$ Nested logit model results for combined area.

\begin{tabular}{|c|c|c|c|c|c|c|}
\hline \multirow[b]{2}{*}{ Descriptor } & \multicolumn{3}{|c|}{ Areas with high air pollution } & \multicolumn{3}{|c|}{ Areas with moderate air pollution } \\
\hline & Coefficient & Std. error & $\begin{array}{c}\text { Significance } \\
\text { level }\end{array}$ & Coefficient & Std. error & $\begin{array}{c}\text { Significance } \\
\text { level }\end{array}$ \\
\hline Health effects & 1.6716 & 0.1527 & $\mathrm{P}<0.001$ & 1.9175 & 0.2137 & $\mathrm{P}<0.001$ \\
\hline $\begin{array}{c}\text { High } \\
\text { particulates }\end{array}$ & 0.9489 & 0.1273 & $\mathrm{P}<0.001$ & 1.6666 & 0.2566 & $\mathrm{P}<0.001$ \\
\hline Foul odors & 0.7810 & 0.0961 & $\mathrm{P}<0.001$ & 0.7854 & 0.1085 & $\mathrm{P}<0.001$ \\
\hline $\begin{array}{l}\text { Reduced } \\
\text { visibility }\end{array}$ & 1.5872 & 0.1641 & $\mathrm{P}<0.001$ & 1.0588 & 0.1504 & $\mathrm{P}<0.001$ \\
\hline Taxes & -0.0104 & 0.0009 & $\mathrm{P}<0.001$ & -0.0132 & 0.0017 & $\mathrm{P}<0.001$ \\
\hline Nest A & 1.0142 & 0.1159 & $\mathrm{P}<0.001$ & 0.7979 & 0.1179 & $\mathrm{P}<0.001$ \\
\hline Nest B & 0.5739 & 0.0680 & $\mathrm{P}<0.001$ & 0.5095 & 0.0653 & $\mathrm{P}<0.001$ \\
\hline Nest C & 0.6916 & 0.0845 & $\mathrm{P}<0.001$ & 0.4447 & 0.0700 & $\mathrm{P}<0.001$ \\
\hline \multicolumn{7}{|c|}{ Goodness of fit criteria } \\
\hline \multicolumn{2}{|c|}{ McFadden's LRI } & \multicolumn{2}{|c|}{0.7708} & \multicolumn{3}{|c|}{0.7280} \\
\hline \multicolumn{2}{|c|}{ Veall-Zimmermann } & \multicolumn{2}{|c|}{0.9565} & \multicolumn{3}{|c|}{0.9460} \\
\hline \multicolumn{2}{|c|}{ Estrella } & \multicolumn{2}{|c|}{0.9997} & \multicolumn{3}{|c|}{0.9993} \\
\hline \multicolumn{2}{|c|}{ Adjusted Estrella } & \multicolumn{2}{|c|}{0.9997} & \multicolumn{3}{|c|}{0.9992} \\
\hline \multicolumn{2}{|c|}{ Cragg-Uhler(1) } & \multicolumn{2}{|c|}{0.9861} & \multicolumn{3}{|c|}{0.9823} \\
\hline \multicolumn{2}{|c|}{ Cragg-Uhler(2) } & \multicolumn{2}{|c|}{0.9899} & \multicolumn{3}{|c|}{0.9862} \\
\hline
\end{tabular}


As is evident, all attribute coefficients have the expected signs. The signs of all attributes, except the price attribute, are positive. This, as consumer preference theory predicts, suggests that any improvement in these attributes would cause an improvement in air pollution, which leads to increased utility. The coefficient for the price attribute is negative, and is also consistent with standard economic theory. All of the air pollution attributes are significant determinants of utility well below the one-percent level. The health effects of air pollution have the largest coefficient in highly polluted areas. Reduced visibility, high particulate counts, and foul odours are ranked second, third, and fourth, respectively. In areas of moderate air pollution, the health effect of air pollution also has the largest coefficient. However, in this case high particulate count, reduced visibility, and foul odours are ranked second, third, and fourth, respectively.

Because it is not possible to interpret the coefficients directly, marginal rates of substitution between non-market attributes and the monetary attribute were estimated. These are reported in Table 4 . These values represent the amount of money individuals would be willing to pay for the specified improvement (as shown in Table 2). Mashhad residents are willing to pay IRR 1,607 (Iranian rials) per month for improvements in health measures if they live in highlypolluted areas and a slightly lower amount, IRR 1,453 per month, if they live in the moderately-polluted areas.

Table 4: Willingness-to-pay for improvement in several aspects of air pollution.

\begin{tabular}{|c|c|c|c|c|}
\hline \multirow{2}{*}{ Attribute } & \multicolumn{2}{|c|}{$\begin{array}{c}\text { Areas with high air } \\
\text { pollution }\end{array}$} & \multicolumn{2}{c|}{$\begin{array}{c}\text { Areas with moderate air } \\
\text { pollution }\end{array}$} \\
\cline { 2 - 5 } & $\begin{array}{c}\text { Willingness-to- } \\
\text { pay (rials month }\end{array}$ & Index & $\begin{array}{c}\text { Willingness-to- } \\
\text { pay (rials month }\end{array}$ & Index \\
\hline Health effects & 1607.30 & 100 & 1452.60 & 100 \\
\hline High particulates & 912.40 & 56 & 1262.60 & 86 \\
\hline Foul odours & 751.00 & 46 & 595.00 & 40 \\
\hline $\begin{array}{c}\text { Reduced } \\
\text { visibility }\end{array}$ & 1526.10 & 94 & 802.10 & 55 \\
\hline
\end{tabular}

Approximately 9500 Rials $=1$ U.S. dollar.

According to the estimates in Table 4, residents of Mashhad living in the areas with high air pollution are willing to pay, on average, IRR 751, IRR 912, IRR 1,526, and IRR 1,607 per household per month for 30\% improvements in foul odours, high particulate counts, reduced visibility, and health effects of air pollution, respectively. Comparable estimates of WTP for the moderatelypolluted neighbourhoods are relatively lower for all four attributes. It is clear that residents of areas subject to moderate air pollution do not consider health improvements to have the same high value that is given to them by residents of heavily-polluted areas. 


\subsection{Comparison of scenario results}

Researchers used the results of equation (7) to estimate improvement in household welfare, for both high pollution and moderate pollution neighborhoods, under each possible scenario (as shown in Table 5). For the baseline scenario (that is, current conditions), the welfare change is zero. Scenario 3, which postulates a $30 \%$ improvement in all four measures of air pollution, yields an estimate of strong positive change in household economic welfare. Under this scenario, Mashhad residents are better-off by IRR 24,950 per household per month in areas with high air pollution, and IRR 21,390 per household per month in areas with moderate pollution (Table 6). Both scenario 5 and 6 show household welfare decreasing, due to health measures $30 \%$ lower than baseline. All these results demonstrate the prominent role of air pollution's health effects in determining the economic well-being of Mashhad households.

Table 5: List of possible outcomes presented to interviewees.

\begin{tabular}{|c|c|c|c|c|c|c|}
\hline Possible changes & \multicolumn{7}{|c|}{ Outcomes } \\
\cline { 2 - 7 } & $1 *$ & 2 & 3 & 4 & 5 & 6 \\
\hline Health effects: & & & & & & \\
\hline $\begin{array}{c}\text { Extra hospital admissions } \\
\text { per month }\end{array}$ & 18 & 18 & 12 & 12 & 24 & 18 \\
\hline Extra deaths per month & 2 & 2 & 1 & 1 & 2 & 2 \\
\hline Pollution effects: & 3 & 3 & 2 & 3 & 4 & 4 \\
\hline $\begin{array}{c}\text { High particulate count } \\
\text { (days per month) }\end{array}$ & 3 & 4 & 3 & 5 & 4 & 5 \\
\hline $\begin{array}{c}\text { Foul odours (days per } \\
\text { month) }\end{array}$ & 3 & 3 & 2 & 2 & 4 & 4 \\
\hline $\begin{array}{c}\text { Reduced visibility (days } \\
\text { per month) }\end{array}$ & 10,400 & 12,480 & 10,400 & 5,200 & 10,400 & 14,560 \\
\hline $\begin{array}{c}\text { Taxes (IRR per } \\
\text { household per month) }\end{array}$ & & & & & & \\
\hline
\end{tabular}

* Baseline.

Table 6: Improvements in household welfare under various scenarios.

\begin{tabular}{|c|c|c|c|c|c|c|}
\hline \multirow{2}{*}{ Particulars } & \multicolumn{7}{|c|}{ Scenarios } \\
\cline { 2 - 7 } & $1^{*}$ & 2 & 3 & 4 & 5 & 6 \\
\hline \begin{tabular}{c} 
Areas with high air pollution \\
\hline $\begin{array}{c}\text { Change in welfare } \\
\text { IIR household }^{-1} \\
\text { month }^{-1} \text { ) }\end{array}$
\end{tabular} & 0 & $-2,087$ & 24,950 & 17,600 & $-21,050$ & $-20,750$ \\
\hline $\begin{array}{c}\text { Changes in welfare } \\
\text { (IRR household }^{-1} \\
\text { month }^{-1} \text { ) }\end{array}$ & 0 & $-2,085$ & 21,390 & 13,830 & $-18,280$ & $-18,000$ \\
\hline
\end{tabular}

* Baseline. 


\section{Conclusions}

Residents of the city of Mashhad, Iran, were surveyed to determine what values they would assign to local air pollution. They were asked to evaluate the following scenarios: $30 \%$ increases or decreases in foul odours, heavy particulate concentrations, reduced visibility, and impaired health, against a baseline of current conditions. By using a choice experiment approach and analyzing survey results with a Nested Logit (NL) model, researchers determined the value that Mashhad residents placed on the environmental effects of air pollution. In addition, researchers estimated the probable changes in household welfare under different possible outcomes associated with different levels of air pollution.

The results of this research indicate that the total economic value gained as the result of a thirty percent improvement in the four measures of air pollution could be estimated at IRR 6,732 million per month (equivalent to US\$708,632) in the areas with high air pollution. In the areas with moderate air pollution, a thirty percent improvement in these pollution measures was estimated as adding IRR 4,571 million per month (equivalent to US\$481,158) to economic value. Assuming common preference functions and shared utility of reduced air pollution in the two types of areas, the total value of a thirty percent improvement in Mashhad's air pollution would amount to close to IRR 11,303 million per month (equivalent to US\$1.19 million).

How could this money be raised and spent? The city could levy various green taxes, including cap-and-trade system (a program to cap emissions and set up a market for exchangeable pollution permits). The city could use these revenues to set up programs to teach Mashhad residents about pollution and how to curb it. It could invest in infrastructure that could reduce air pollution, such as subways, electric cars, dedicated safe bicycle lanes. Any such initiatives should of course be studied thoroughly before implementation.

\section{References}

[1] WCED_-World Commission on Environment and Sustainability. 1987. Our common future. Oxford University Press, New York.

[2] Gurluk, S. 2006. The estimation of ecosystem services' value in the region of Misi rural development project: Results from a contingent valuation survey. For. Pol. Econom. 9, 209-218.

[3] Dagsvik, J.K., Wennemo, T., Wetterwald, D.G., Aaberge, R. 2002. Potential demand for alternative fuel vehicles. Transp. Res. Part B 36, 361384.

[4] Mousavi, M. 2003. Mashhad air pollution program. Environment Office of Khorasan Razavi.

[5] Loomis, J., Kent, P., Strange, L., Fausch, K., Covich, A. 2000. Measuring the total economic value of restoring ecosystem services in an impaired river basin: Results from a contingent survey. Ecol. Econ. 33, 103-117. 
44 Environmental Health and Biomedicine

[6] Muller, R.A., Diener, A.A. 1997. Economic valuation of air quality in regional municipality of Hamilton-Wentworth. Department of Economics, McMaster University, Hamilton, Ontario, Canada.

[7] Green, W.H. 1993. Econometric Analysis. Second Edition. New York: Macmillan Publishing Company.

[8] Adamowicz, W., Louviere, J.J., Williams, M. 1994. Combining revealed and stated preference methods for valuing environmental amenities. J. Environ. Econom. Management 26, 271-92.

[9] Ortúzar, J. de D., Willumsen, L.G. 2001. Modelling Transport. Third Edition. John Wiley and Sons, Chichester.

[10] Hensher, D.A., Rose, J., Greene, W.H. 2004. Applied choice analysis: A primer. Cambridge University Press: Cambridge.

[11] Hausman, J.A., McFadden, D. 1984. Specification tests for the multinomial logit model. Econometrica 52, 1219-1240.

[12] Bergmann, A., Hanley, N., Wright, R. 2006. Valuing the attributes of renewable energy investments. Ener. Po. 34, 1004-1014. 